\title{
Congenital Gangrene in a Premature Newborn: A Case Report
}

\author{
Assetou Cissouma1*, Mamadou B. Coulibaly², Djibril Kassogué ${ }^{3}$, Hachimi A. Poma1, \\ Moussa Diassana4, Bathio Traoré4, Aly Diallo4, Layes Touré ${ }^{5}$, Ternan Traoré5, Moussa Kanté6, \\ Abdoulaye Kissima-Traoré7
}

\author{
${ }^{1}$ Pediatric Service, Sikasso Hospital, Sikasso, Mali \\ ${ }^{2}$ Pediatric Surgery Service, Sikasso Hospital, Sikasso, Mali \\ ${ }^{3}$ Pediatric Service, Timbuktu Hospital, Timbuktu, Mali \\ ${ }^{4}$ Surgery General Service, Sikasso Hospital, Sikasso, Mali \\ ${ }^{5}$ Orthopedic and Trauma Surgery Service, Sikasso Hospital, Sikasso, Mali \\ ${ }^{6}$ Anesthesia and Intensive Care Service, Sikasso Hospital, Sikasso, Mali \\ ${ }^{7}$ Cardiology Service, Sikasso Hospital, Sikasso, Mali \\ Email: ${ }^{*}$ cis_astou@yahoo.fr
}

How to cite this paper: Cissouma, A., Coulibaly, M.B., Kassogué, D., Poma, H.A., Diassana, M., Traoré, B., Diallo, A., Touré, L., Traoré, T., Kanté, M. and Kissima-Traoré, A. (2021) Congenital Gangrene in a Premature Newborn: A Case Report. Open Journal of Pediatrics, 11, 393-397.

https://doi.org/10.4236/ojped.2021.113036

Received: June 16, 2021

Accepted: August 20, 2021

Published: August 23, 2021

Copyright $\odot 2021$ by author(s) and Scientific Research Publishing Inc. This work is licensed under the Creative Commons Attribution International License (CC BY 4.0)

http://creativecommons.org/licenses/by/4.0/

\begin{abstract}
Introduction: Congenital limb gangrene is a rare pathology. In the majority of cases, no cause is identified and its treatment is not codified. Observation: 29-week premature newborn, female from poorly followed twin pregnancy. Clinical examination at admission found an unstable neonate, the presence of necrosis of the left hand and forearm well limited, with absent humeral pulse and absence of hand movement. Surgical treatment was scheduled for amputation of the limb after the agreement of the parents whose postoperative follow-ups were simple. Conclusion: Congenital gangrene remains a rare entity in neonatology.
\end{abstract}

\section{Keywords}

Gangrene, Upper Limb, Newborn, Prematurity

\section{Introduction}

Congenital gangrene of the extremities of the newborn is a rare phenomenon in neonatology in many cases; no etiological factors are demonstrated [1] [2]. The cases described focus on the mother-fetal pathologies involved and emphasize urgent surgical treatment in case of proven ischemia of a limb [3]. Nevertheless, any neonatal gangrene suggests intrauterine etiopathogenesis; several risk factors may be related to congenital gangrene. They are mentioned: prematurity, sys- 
temic infection, maternal diabetes, dystocic presentations, hypothermia, and congenital heart disease [4] [5]. Management is not codified and treatment is based on antibiotic therapy, heparinotherapy and surgical amputation [1] [2] [3] [4] [5]. We report a case of congenital gangrene of the collected hand in the pediatric department of the Sikasso Hospital.

\section{Patient and Observation}

This is a premature female newborn of (29 weeks) from a twin pregnancy poorly followed by no blood or radiological assessment performed in a 25 -year-old mother with no known pathological history G4P4V3A0. The delivery took place vaginally in a community health center with G1 female weighing $1030 \mathrm{~g}$ Apgar unspecified and G2 male weighing $1010 \mathrm{~g}$ stillborn. Addressed to our service for respiratory distress and cyanosis of the left hand. From birth, the newborn presented a phlyctene that was aggravated 48 hours later by a total cyanosis of the left hand, hence the decision to transfer it to our training for further management. Clinical examination at admission found a newborn that was unstable on planes: hemodynamic, neurological and respiratory, weighing $980 \mathrm{~g}$, Size $=34$ $\mathrm{cm}, \mathrm{PC}=24 \mathrm{~cm}$, Temperature $35.1^{\circ} \mathrm{C}$ with saturation at $95 \%$. Presence of necrosis of the hand and left forearm well limited, with absent humeral pulse and absence of movement of the hand (Figure 1). The biological assessment showed an infectious syndrome, anemia at $7 \mathrm{~g} / \mathrm{dl}$ with a prothrombin level (TP) at $60 \%$ and a normal activated cephalin time (TCA). The newborn was put on triple antibiotic therapy, blood transfusion, caffeine citrate, hydroelectrolytic infusion with local care. Surgical treatment was scheduled for amputation of the limb after the agreement of the parents whose postoperative follow-ups were simple (Figure 2). The newborn was discharged to a hospitalized J20 with a weight at $1045 \mathrm{~g}$ and a weight gain at $15 \mathrm{~g} / \mathrm{kg} /$ day and scarring (Figure 3). The infant was followed in the kangaroo mother program and had a good prognosis. The newborn was referred to the orthoprosthetist center for equipment.

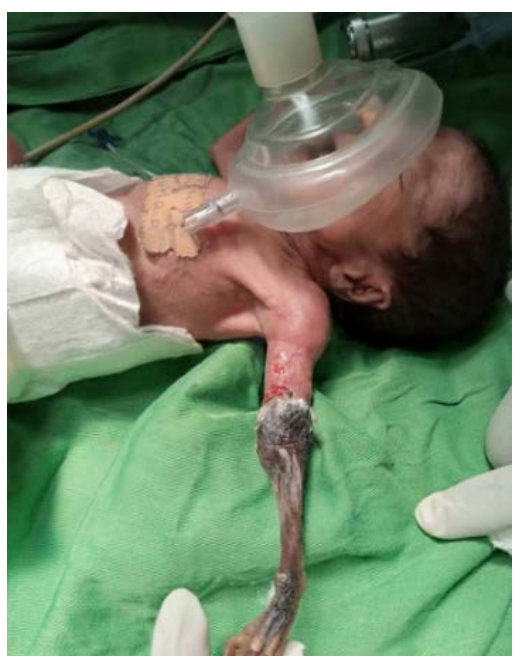

Figure 1. Necrosis of the left hand. 


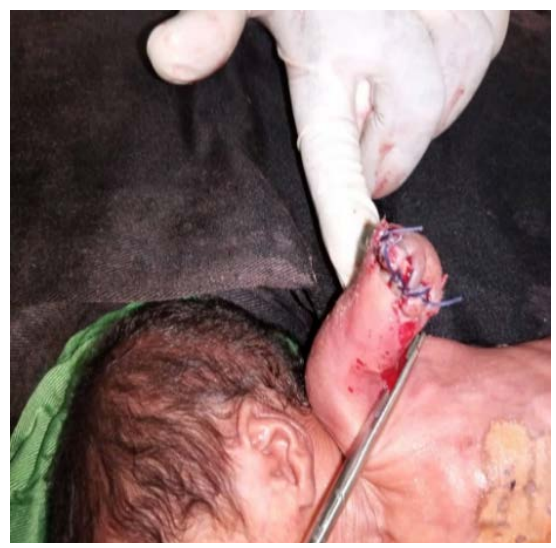

Figure 2. Amputated hand.

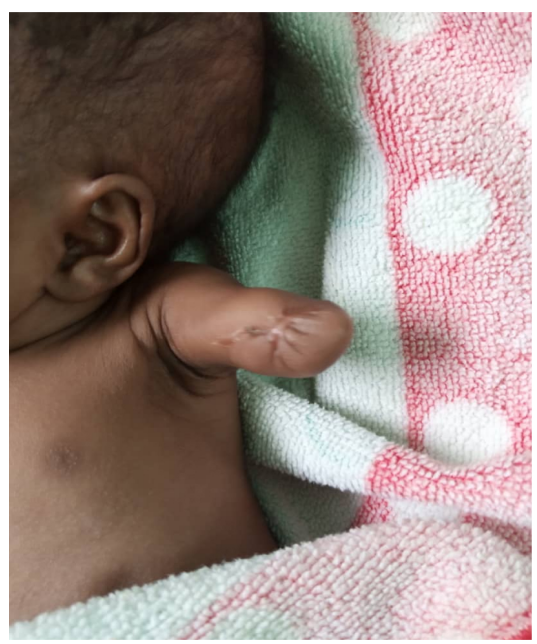

Figure 3. Wound healing.

\section{Discussion}

Gangrene of the extremities in newborns is extremely rare [1] [2] [5]. The first description is attributed to Martini (1828) quoted by Blank et al. [5] [6]. Acute ischemia of the limbs is most often caused by thromboembolic phenomena [4] [5] [6] [7] [8]. Several risk factors such as gestational diabetes, prematurity, congenital heart disease, obstetric trauma, polycythemia, sepsis etc. have been cited in the literature as predisposition factors for congenital gangrene of the extremities [1] [2] [3] [4] [5]. According to some authors, its cause is not identified in most cases. [1] [3] [4] [9]. However, other authors find that arterial insufficiency can lead to limb ischemia either by intrauterine compression or by arterial thrombosis [5] [6]. The management of these newborns has two components: the first is medical treatment based on antibiotic therapy, whether or not combined with heparinotherapy. The second is surgical but given the major psychosocial impact for the patient and his family as well as the tissue regeneration power of the newborn [2] [5] [10]. There is a trend towards procrastination by not proceeding to amputation from the outset pending a definitive demarcation of the gangrene part but in the case of established gangrene, amputation is the 
treatment of choice. Nevertheless, by reviewing the literature, it was found that almost all reported cases proceeded to urgent amputation [3] [4] [5]. On the other hand, timothy and cervix reported a case of thrombectomy performed at H10 of life in a newborn with necrosis of the hand [6]. Thus Ufuk Aydin and cervix successfully treated a case of congenital gangrene of the upper limb through negative pressure therapy [10]. Our attitude was in accordance with the algorithm for the management of acute limb ischemia lesions of children under three years of age proposed by Geordiadis et al. [11] which states that in case of irreversible gangrene it is necessary to amputate.

\section{Conclusion}

Congenital gangrene remains a rare entity in neonatology; only a dozen cases have been reported by the literature. The pathophysiology of these cases of congenital gangrene remains poorly established, as does the etiology. Therapeutic management is the subject of controversy between those who advocate amputation from the outset and those who lean more towards conservative treatment at first.

\section{Parental Consent}

Informed consent from the parents was obtained for the publication.

\section{Contributions by Authors}

All the authors contributed to the realization of this work. All of them read and approved the final version of the manuscript.

\section{Conflicts of Interest}

The authors do not declare any conflict of interest.

\section{References}

[1] Al-Salem, A.H, Mohamed Ibrahim Naga, Ashraf Alnosair A, Mohamed Ramadan Abdallah (2014) Neonatal Gangrene of the Extremity: A Report of Three Cases and Review of the Literature. Journal of Pediatric Surgical Specialties, 8, 28-32.

[2] Yaokreh, J.-B., Kouamé Yapo, G.S., Tembely, S., Kobinan Rufin, D. and Odehouri-Koudou, T.H. (2014) Congenital Gangrene of the Upper Limb. Journal of Perinatal Medicine, 6, 57-59. https://doi.org/10.1007/s12611-014-0263-y

[3] Sahu, B. and Panigrahi, R. (2011) Forearm Gangrene Following Distraction Injury at Elbow in a Neonate. Indian Journal of Orthopaedics, 45, 479-480. https://doi.org/10.4103/0019-5413.83136

[4] Singh, J., Rattan, K.N., Gathwala, G. and Kadian, Y.S. (2011) Idiopathic Unilateral Lower Limb Gangrene in a Neonate. Indian Journal of Dermatology, 56, 747-748. https://doi.org/10.4103/0019-5154.91845

[5] Dakouré, P.W.H., Béogo, R., Barro, D., Somé, D.A., Cessouma, R. and Kambou, T. (2010) Intrauterine Ischemia of the Right Upper Limb and Hemiface: A Case Report. Chirurgie de la Main, 29, 121-124. https://doi.org/10.1016/j.main.2010.02.004 
[6] Blank, J.E., Dormans, J.P. and Davidson, R.S. (1996) Perinatal Limb Ischemia: Orthopaedic Implications. Journal of Pediatric Orthopaedics, 16, 90-96. https://doi.org/10.1097/01241398-199601000-00018

[7] Tanvig, M., Jørgensen, J.S., Nybo, M. and Zachariassen, G. (2011) Intrauterine Extremity Gangrene and Cerebral Infarction at Term: A Case Report. Case Reports in Pediatrics, 36, 3517. https://doi.org/10.1155/2011/363517

[8] Ulrich, T.J., Ellsworth, M.A. and Lang, T.R. (2014) Emergent Thrombectomy in a Neonate with an Upper Extremity Arterial Thrombus. American Journal of Perinatology Reports, 4, 41-44. https://doi.org/10.1055/s-0034-1370355

[9] Sellami, K., Chaabane, H., Chaari, I., Bahloul, E., Masmoudi, A., Mseddi, M. and Turki, H. (2015) Unilateral Sub-Ungeal Necrosis in a Premature Newborn Annales of Dermatology and Venereology. Annales de Dermatologie et de Vénéréologie, 142, S543. https://doi.org/10.1016/j.annder.2015.10.256

[10] Aydin, U., Ozgenel, Y. and Kanturk, R. (2010) Vacuum-Assisted Closure Therapy in Newborn Gangrene. Journal of Plastic, Reconstructive \& Aesthetic Surgery, 63, e277-e279. https://doi.org/10.1016/j.bjps.2009.05.049

[11] Geordiadis, G.S. and Lazarides, M.K. (2009) Comment on "Management of Limb Ischemia in the Neonate and Infant" (Eur J Vasc Endovasc Surg 2009; 38: 61-65). A Proposed Algorithm for Optimal Results. European Journal of Vascular and Endovascular Surgery, 38, 531-532. 